\title{
Chlamydia and Vaginitis in Sexually Active Females: Classical Identification Methods for Effective Control
}

\section{Niemogha Mary $\mathbf{T}^{1}$, Smith Stella I ${ }^{1}$, Goodluck Helen $\mathbf{A}^{1}$, Gbaja-biamila Titi ${ }^{1}$, Fesobi Toun', Umurhuru Amos ${ }^{2}$, Oduyebo Oyinlola $\mathrm{O}^{3}$, Adeiga Adesina $\mathrm{A}^{1}$, Solayide A Adesida ${ }^{1}$, Adagbada Ajoke $\mathbf{O}^{1}$, Bamidele Tajudeen ${ }^{1}$ and Musa Adesola $\mathrm{Z}^{1}$}

${ }^{1}$ Nigeria Institute of Medical Research, Yaba, Lagos, ${ }^{2}$ Infirmary Laboratory, Ilasa, Lagos, ${ }^{3}$ Department of Medical Microbiology/Parasitology, College of Medicine, University of Lagos, Nigeria

\begin{abstract}
Laboratory diagnosis of Chlamydia and vaginitis in sexually active females has been limited by unavailability of a sequential method/rapid technique for simple diagnosis. Six hundred (600) adult females from hotel/brothel, Sexually Transmitted Infections (STIs) Clinic, Obstetrics/Gynaecology Clinic, Family Planning Clinic and Healthy controls were investigated for Chlamydia, Candida, trichomoniasis and bacterial vaginosis (BV). This was done using microscopy: wet mount, stained vaginal secretion and stained smear after culture. Results showed that there were $72 \%$ infections in the female groups. The brothel and STI group had infection in the range (70-86\%). Chlamydial infection was highest in the STI group while Candida infection was highest in the healthy (control) females. Bacterial vaginosis was distributed in all groups. As $p$ value increased, $f$-value increased indicating constant co-infection of Candida and BV in Chlamydia positive females. Microscopy by direct detection from sample and stained smear after culture were in the range: 56 $86 \%$. Direct microscopy for BV was $78.5 \%$ and stained smear after culture, $57.1 \%$. Sensitivity and specificity of the techniques showed that detection of Chlamydia was less sensitive by direct microscopy of sample but sensitivity and specificity of stained smear after culture were high. Immunoassay (32.2\%) was also less sensitive. Sensitivity and specificity of wet mount microscopy for Candida, Trichomoniasis and BV were in the range $62.5-80 \%$ and $62.5-97.8 \%$ respectively. Wet mount has high sensitivity and specificity for detecting agents of vaginitis and may be useful for routine use and for diagnosis where disease is absent, thus, making identification more cost effective.
\end{abstract}

\section{Keywords: Chlamydia, Culture, Microscopy, Staining techniques, Vaginitis}

Received 27 October 2010/ Accepted 16 December 2010

\section{INTRODUCTION}

Chlamydial infection and vaginitis constitute problems in the female genital tract (Cates et al., 1990) and symptoms of acute vulvovaginitis remain one of the most common reasons for women's healthcare visits. Chlamydia trachomatis is the most common cause of sexually transmitted infection in the world (CDC, 1993). Other pathogens that make up vaginitis are Candida albicans (Candidiasis), Trichomonas vaginalis (Trichonomiasis) and Bacterial vaginosis. Bacterial vaginosis is the single entity caused by many organisms including Gardnerella vaginalis, Mobilincus spp, Mycoplasma hominis, Bacteroides spp, Gram positive anaerobic cocci (Peptococcus and Peptostreptococcus) species (Willet and Centor, 2005; Lowe et al., 2009). These organisms and other sexually transmitted pathogens are associated with high risk for HIV infection (Hilber et al., 2010) by causing genital lesions which facilitate viral entry or by increasing the number of target cells for HIV (activated monocytes) (Greenblatt et al., 2005).

Complications which include cervicitis, urethritis, 
endomethritis and pelvic inflammatory disease (PID), increase incidence of ectopic pregnancy and infertility are common (Friedek et al., 2004). Although Chlamydia and vaginitis are known to cause serious problems in female sexual and reproductive health (Wilson et al., 2005), yet diagnostic methods for Chlamydia are nondefinitive. The use of test kits is uncertain, the tissue culture methods using McCoy cell lines are expensive and the use of embryonated hen's eggs is laborious (Stamm et al., 1983; Jespersen et al., 2005). The non - culture method using Chlamydiazyme and Microtrak direct fluorescent antibody, Sylva Micro-trak enzyme immunoassay (EIA) using DFA, PCR and DNA probe analysis with varying sensitivity and specificity are expensive and beyond the reach of most laboratories (Black, 1997; New Hall et al., 1999; Lowe et al., 2009). These issues constitute problems in the diagnosis of Chlamydia and the aspect of identifying Candida albicans, Trichomonas vaginalis and Bacterial vaginosis (BV) has not been properly resolved.

Cultivation of micro-organisms has been shown to be gold standard for phenotypic identification of organisms (Jespersen et al., 2005). Microscopy and staining techniques have also been shown to reveal micro-organisms causing genital infections. Even deep seated infections with unknown route or origin have been deduced using the microscope. Stained smears using gram-stain and other standard stains have been used to detect and reveal intracellullar existence of Chlamydia (Schacter, 1990). Additionally, the sensitivity and specificity of these methods have been highlighted by research scientists (Hadgu and Stemberg, 2009), and values obtained were used to grade usefulness in diagnosis/detection of diseases.

In Nigeria, as in other African countries, the paucity of data concerning Chlamydia and vaginitis has created vacuum in diagnosis of these infections. Besides no such diagnostic methods are in place. Hence, it is important to have a baseline data upon which further investigations could be made and also institute straight forward combined methods for prompt diagnosis. This study therefore evaluates Chlamydia and vaginitis in sexually active females from various socioeconomic backgrounds. Moreover, it is aimed at providing a harnessed investigation system in the laboratory for identifying Chlamydia and vaginitis which invariably will be merged into a single linear procedure for proper and prompt diagnosis in our setting.

\section{SUBJECTS, MATERIALS AND METHODS Subjects}

A total of six hundred (600) participants were randomly selected from various groups constituting females from Hotels / Brothels (250), STI clinic (100), Obstetrics /Gynaecology centre (100), family planning clinics (50) and apparently healthy undergraduates (100). The participants were from both private and government medical centres in Lagos metropolis. The laboratory investigations were carried out at the Molecular Biology Division of the Nigerian Institute of Medical Research (NIMR), Yaba, Lagos and Infirmary Laboratory, Lagos.

\section{Ethical Consideration}

Proposal was approved by Institutional Review board (IRB) of NIMR, Yaba. Informed consent was obtained from the participants.

\section{Sample Collection}

From each participant, four swabs were collected: two endocervical swabs (ECS) and two High Vaginal Swabs (HVS). One HVS was used for microscopy and the other for culture on artificial media. One ECS for immunoassay and the other for culture in Embryonated Hen's Eggs (EHE). Samples were transported to the laboratories using Hanks transport medium (Black, 1997).

\section{Laboratory Investigation of Samples Wet Mount}

Microscopy was carried out on vaginal extracted secretions by squeezing swab of sample in $0.5 \mathrm{ml}$ of normal saline for yeast cells and other organisms. For detection of Candida and Trichomonas vaginalis, one drop each of the extracted vaginal sample was placed on opposite sides of a clean slide. A drop of $10 \%$ potassium hydroxide was added to one of the fluid and sniffed for fishy odour (whiff test); positive reaction indicates bacterial vaginosis. Other Amsel criteria were applied to detect BV. They include detection of clue cells, $\mathrm{pH}>4.5$ ( $\mathrm{pH}$ strip of range 4.0-7.0) of the vaginal secretion and homogenous discharge (Amsel et al., 1983). The second preparation was covered with a cover slip and observed for oval cells / hyphae to detect Candida. Jerky movement was used to detect Trichomonas species (Romanik and Martinosian, 2004). 


\section{Dry Mount}

This screening test was done to detect pathogens directly from freshly collected samples. A drop of vaginal sample which was extracted in $0.5 \mathrm{ml}$ of 0.2 normal saline placed on slide and allowed to air dry. Thereafter, they were Gram stained (Nugent et al., 1991). Smears were also made directly from endocervical samples before culture and stained with Giemsa for Chlamydia while Gram staining was applied to detect other pathogens. This was done to screen for pathogens directly from freshly collected samples.

\section{Culture in Synthetic Media}

High Vaginal Swab was cultured on various media. For Candida, sample was cultured on Sabouraud Dextrose Agar (SDA). For Trichomonas vaginalis culture was done on Cysteine Peptone Liver Maltose Agar (CPLM OXOID, Basingstoke). Culture was incubated aerobically for $24 \mathrm{hrs}$ at $37^{\circ} \mathrm{C}$. Facultative culture of samples from female vagina was done for BV in primary isolation medium using Columbia Agar with colistin and nalidixic acid (CAN) (OXOID, Basingstoke) supplemented with $1 \%$ proteosepeptone and $5 \%$ whole human blood. This was done to identify Gardnerella vaginalis and other likely pathogens. Vaginal samples were swabbed and plated on CAN and incubated in carbon dioxide candle extinction jar at $37^{\circ} \mathrm{C}$ for (24- 48) hrs. Thereafter, growth was analysed for likely pathogens (Cowan and Steel, 1993; Romanik et al., 2005). Anaerobic cultures were not done because of unavailability of some necessary reagents.

\section{Culture in Embryonated Hen's Eggs (EHE)}

Embryonated Hen's eggs (EHE) were drilled using the dental equipment (Reco-Dental, Wicsbaden, West Germany mot: 117821). After cleaning each egg with $70 \%$ ethanol, the round blade provided was used to make a cut at the apex of the egg such that the upper part of the egg formed a cap. The extracted endocervical sample in phosphate buffer saline was inoculated into the eggs by using syringes to penetrate the chorio-allantoic membrane. Egg was inoculated and sealed with a label to avoid exposure to air contaminants. Incubation was done for two weeks at $37^{\circ} \mathrm{C}$. Every other day, eggs were candled and impression smears were made and stained with Giemsa. Thereafter, they were viewed for inclusion bodies. After screening eggs for dwarfening of embryo, those that looked hazy were selected and passage into another set of EHE (Schacter, 1967)

\section{Microscopy and Analysis after Culture in various Media}

After culture on various media, Embryonated Hen's Egg (EHE), Sabouraud Dexrose Agar (SDA), Cysteine Peptone Liver Maltose Agar (CPLMA) and Columbia Agar with colistin and nalidixic acid, smears of growth/colonies were made and stained with iodine (20\%). Confirmatory staining was done with Giemsa for Chlamydia and Gram stain for other pathogens. Thereafter they were examined for Chlamydia, Candida, Trichomonas and agents of Bacterial vaginosis (Moncada et al., 1990)

\section{Immunoassay}

Following manufacturer's instructions, samples were assayed using qualitative test kits, QuickVue (Quidel, USA) and Diaspot, (America) whereby the principles are based on AntigenAntibody reaction. Both positive and negative test control were included in each pack.

\section{Storage of Organisms}

Strains of $C$. trachomatis were harvested into 2SP (0.2M sucrose in 0.02M phosphate buffer, $\mathrm{pH} 7.0$ ) in $1 \mathrm{ml}$ amount with antibiotics (Schacter, 1990) i.e. $0.2 \%$ Streptomycin or $0.5 \%$ Erythromycin (to wade off bacterial contaminants) and frozen at $70^{\circ} \mathrm{C}$ in aliquots. Individual aliquots when needed were thawed immediately prior to use and cultured in $2-5 \mathrm{P}$ to give $(10-20)$ inclusions per x400 field for $100 \mu \mathrm{g}$ inoculum. This will be used for typing with monoclonal antibodies in subsequent studies.

\section{Data Analysis}

This was done based on bimodal distribution of observed values. $P$-values for statistical tests of significance was by the level of alpha $=0.05$ which requires a $P$-value to be less than 0.005 before considering difference to be statistically significant. Sensitivity and specificity estimates were obtained by considering Embryonated Hen's egg culture as "gold standard".

\section{RESULTS}

Microscopy of Stained smears from Vaginal Secretion and Smear of Growth after Culture Positive Chlamydia stained with Giemsa was shown by characteristic brownish-purple cytoplasmic inclusion (Figure 1). 
Candida appeared as small (2 to $4 \mu \mathrm{m}$ ), oval or budding yeast like cells and pseudomycelial element which were strongly gram positive. Trichomonas vaginalis appeared as oval shaped with pointed apex. Gram stain of vaginal secretions from women without bacterial vaginosis showed a predominance of gram positive bacilli (Lactobacilli) and a few other bacteria. Those from women with BV showed large numbers of small, gram-negative coccobacilli (G. vaginalis). About half of the cases had gram-negative to gram variable, thin curved rods consistent with Mobilincus species.

Table 1: Infection Rate among Category of Women Enrolled in the Study

\begin{tabular}{|l|l|l|l|l|l|l|}
\hline Location & $\begin{array}{l}\text { Number } \\
\text { tested }\end{array}$ & $\begin{array}{l}\text { Number } \\
\text { with } \\
\text { infections } \\
(\%)\end{array}$ & $\begin{array}{l}\text { Chlamydia } \\
(\%)\end{array}$ & $\begin{array}{l}\text { Candida } \\
(\%)\end{array}$ & $\begin{array}{l}\text { Trichomonas } \\
(\%)\end{array}$ & $\begin{array}{l}\text { Bacterial } \\
\text { Vaginosis } \\
(\%)\end{array}$ \\
\hline Brothel/ Hotel & 250 & $212(85)$ & $30(14)$ & $70(33)$ & $12(6)$ & $100(47)$ \\
\hline STI Clinic & 100 & $70(70)$ & $15(21)$ & $20(29)$ & $5(7)$ & $30(43)$ \\
\hline $\begin{array}{l}\text { Obstetric and } \\
\text { Gynecology }\end{array}$ & 100 & $61(61)$ & $10(16)$ & $30(30)$ & $1(2)$ & $20(33)$ \\
\hline $\begin{array}{l}\text { Family Planning } \\
\text { Clinic }\end{array}$ & 50 & $43(86)$ & $5(12)$ & $15(35)$ & $3(7)$ & $20(47)$ \\
\hline $\begin{array}{l}\text { Healthy Group/ } \\
\text { Undergraduates }\end{array}$ & 100 & $47(47)$ & $2(4)$ & $25(43)$ & $0(0)$ & $20(43)$ \\
\hline Total & 600 & $433(72)$ & $62(14)$ & $160(37)$ & $21(5)$ & $190(44)$ \\
\hline
\end{tabular}

$$
F=6.82 ; P<0.05^{\prime}, X^{2}=35.03
$$

Table 2: Detection Rate of Chlamydia and Agents of Vaginitis by various Methods

\begin{tabular}{|l|l|l|l|l|l|}
\hline $\begin{array}{l}\text { Microbial } \\
\text { Pathogens }\end{array}$ & $\begin{array}{l}\text { Direct } \\
\text { Microscopy of } \\
\text { stained } \\
\text { Samples (\%) }\end{array}$ & $\begin{array}{l}\text { Immuno- } \\
\text { assay (\%) }\end{array}$ & $\begin{array}{l}\text { Wet Mount } \\
(\%)\end{array}$ & $\begin{array}{l}\text { Microscopy of } \\
\text { Culture } \\
(\%)\end{array}$ & $\begin{array}{l}\text { stained smear } \\
\text { after culture } \\
(\%)\end{array}$ \\
\hline $\begin{array}{l}\text { Chlamydia } \\
\text { trachomatis (62) }\end{array}$ & $35(56.4)$ & $20(32)$ & NA & $50(80.6)$ & $28(56)$ \\
\hline $\begin{array}{l}\text { Candida albicans } \\
\text { (160) }\end{array}$ & $100(62.5)$ & NA & $120(75)$ & $\begin{array}{l}105 \\
(65.6)\end{array}$ & $60(57)$ \\
\hline $\begin{array}{l}\text { Trichomonas } \\
\text { vaginalis (21) }\end{array}$ & $18(85.7)$ & NA & $18(85.7)$ & $15(71)$ & $86.6 \%$ \\
\hline $\begin{array}{l}\text { Bacterial } \\
\text { vaginosis (190) }\end{array}$ & $110(57.9)$ & NA & $130(68.4)$ & $\begin{array}{l}140 \\
(73.68)\end{array}$ & $80(42.1)$ \\
\hline
\end{tabular}

$\mathrm{NA}=$ not applicable

\section{Relative Distribution of Chlamydia and Other Infections}

There was a net distribution of $72 \%$ of infection amongst the different groups. The brothel/hotel based, STI clinic and the family planning groups had $70-86 \%$ infections. Occurrence of Chlamydia was highest amongst those attending STI (21\%) clinic, followed by brothel/hotel (14\%) based females. The least for Chlamydia were the apparently healthy individuals.

Candidiasis was highest amongst the apparently healthy undergraduates (43\%) while the Obstetrics/Gynaecology, hotel and Family Planning (FP) were in the range (30-35\%). Trichomonas vaginalis was $7 \%$ for STI and FP females and bacterial vaginosis infections were in the range $33-47 \%$ for all female groups with the most occurring in the STI clinic and brothel groups (Table 1).

Association of Chlamydia with other Pathogens in the various Female Groups

The STI females who had the highest distribution of Chlamydia (21\%) were followed by hotel/brothel based group (14\%). The association of Chlamydia with Candida and BV gave the value $p<0.05$ which was significant in the brothel/hotel and STI Clinic groups while the value for Chlamydia was insignificant in the control group (undergraduates). An association of $x^{2}=$ 35.03 for the STI and O/G groups showed that those within these categories are likely to encounter Chlamydia and Candida. Co-infection of Chlamydia with other pathogens were shown 
by the significant values of $p<0.05$ and $f=6.82$. As $p$-value increased, $f$-value also increased showing that Chlamydia and other pathogens coinfect in the various symptomatic and asymptomatic individuals (Table 1). The pie chart illustration (Figure 2) shows Chlamydia at $50^{\circ}$ $(14.31 \%)$ with adjacent BV and Candida at $158^{\circ}$ $(43.87 \%)$ and $133^{\circ} \quad(36.31 \%)$ respectively. Trichomonas completed the circle with $18^{0}$ $(4.84 \%)$. This chart indicates interlocking relationship of the pathogens.

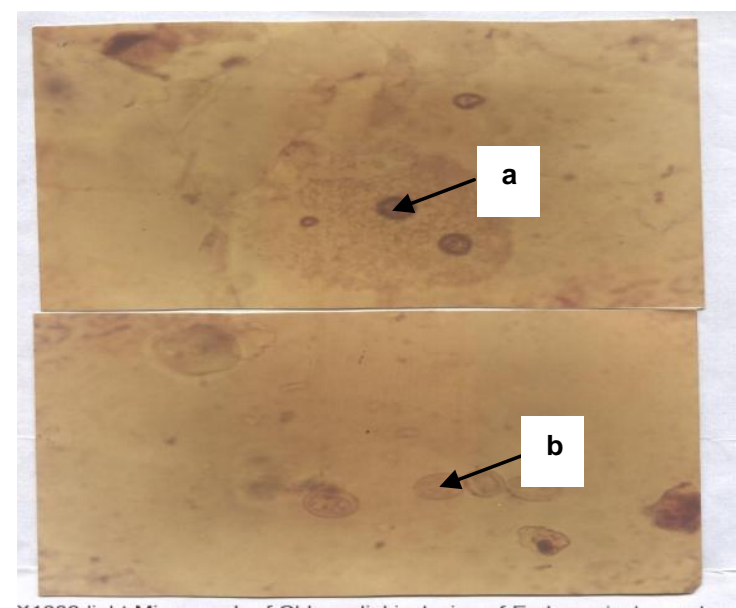

X100 Magnification Light Micrograph

a: shows inclusions containing elementary bodies or infectious particle of Chlamydia, with a resistant rigid envelop and metabolically inactive. $b$ : shows inclusions containing reticulate or initial bodies of Chlamydia. It is metabolically active and has a fragile envelope

Figure 1: Chlamydia inclusions of Endocerical Sample Grown in Embryonated Hen's Egg
Comparative Detection of Chlamydia and Agents of Vaginitis by Various Methods

Direct detection of Chlamydia and agents of vaginitis showed Giemsa staining of endocervical sample, $35(56.4 \%)$ for Chlamydia while wet mount for Candida, Trichomonas and BV revealed pathogens in the range (68.4-85.76\%). Immunoassay was $32 \%$ for Chlamydia. Culture revealed growth of pathogens in the range (65.6$80.6 \%$ ). Microscopy after staining detected $57.9 \%$ for BV and $62.5 \%$ for Candida respectively while $42.1 \%$ for BV showed incomplete culture since anaerobes were not cultivated (Table 2). Growth of Chlamydia in EHE yielded $80.6 \%$, an indication that the embryonated hen's egg support intracellular existence of the pathogens (Figure 1 and 2).

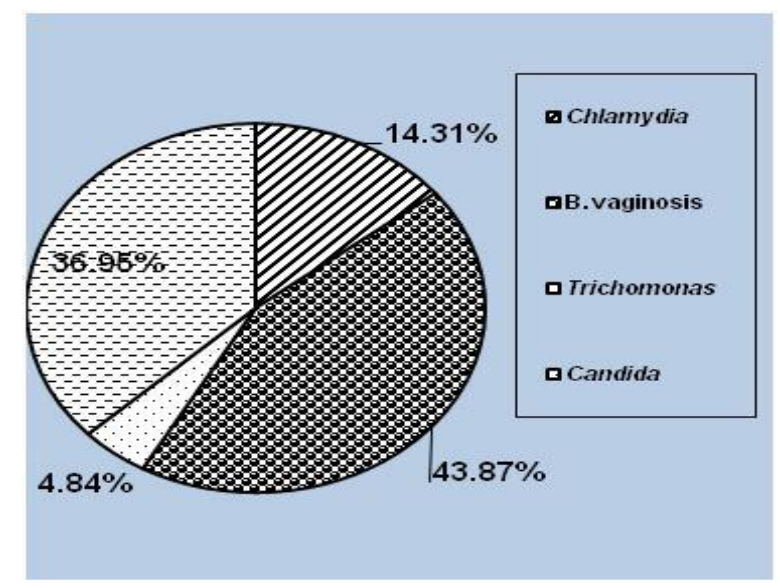

Figure 2: Distribution of Chlamydia and other Pathogens among Groups of Sexually Active Women

Table 3: Comparison of Identification of Chlamydia and Agents of Vaginitis Direct from Stained Samples

\begin{tabular}{|c|c|c|c|c|c|}
\hline \multirow{2}{*}{$\begin{array}{c}\text { Direct Microscopy } \\
\text { of Infectious }\end{array}$} & Positive & Negative & Total No & $\begin{array}{c}\text { Sensitivity } \\
(\%)\end{array}$ & $\begin{array}{c}\text { Specificity } \\
(\%)\end{array}$ \\
\cline { 2 - 5 } & 35 & 5 & 40 & $56.4 \%$ & - \\
\hline $\begin{array}{c}\text { Chlamydia } \\
+\end{array}$ & 27 & 233 & 260 & - & - \\
- & 100 & 20 & 120 & 62.5 & -85.7 \\
\hline $\begin{array}{c}\text { Candida } \\
+\end{array}$ & 60 & 120 & 180 & - & - \\
\hline $\begin{array}{c}\text { Trichomonas } \\
+\end{array}$ & 18 & 18 & 36 & 85.7 & - \\
\hline $\begin{array}{c}\text { Bacterial vaginosis } \\
+\end{array}$ & 110 & 11 & 114 & & - \\
\hline & 30 & 60 & 170 & 78.5 & 62.5 \\
\hline
\end{tabular}


Table 4: Comparison of Stained Smears of Chlamydia and Agents of Vaginitis after Culture

\begin{tabular}{|c|c|c|c|c|c|}
\hline \multirow{2}{*}{ Culture } & \multicolumn{2}{|c|}{ Culture } & \multirow{2}{*}{ Total No } & \multirow{2}{*}{ Sensitivity } & \multirow{2}{*}{ Specificity } \\
\hline & Positive & Negative & & & \\
\hline $\begin{array}{l}\text { Chlamydia } \\
+ \\
-\end{array}$ & $\begin{array}{c}28 \\
7\end{array}$ & $\begin{array}{c}34 \\
231\end{array}$ & $\begin{array}{c}62 \\
238 \\
\end{array}$ & $\begin{array}{c}80 \\
-\end{array}$ & $\begin{array}{c}- \\
87.1\end{array}$ \\
\hline $\begin{array}{l}\text { Candida } \\
+ \\
-\end{array}$ & $\begin{array}{l}60 \\
20\end{array}$ & $\begin{array}{l}100 \\
120\end{array}$ & $\begin{array}{l}160 \\
140\end{array}$ & $\begin{array}{c}75 \\
-\end{array}$ & $\begin{array}{r}- \\
54.5\end{array}$ \\
\hline $\begin{array}{l}\text { Trichomonas } \\
+ \\
-\end{array}$ & $\begin{array}{c}13 \\
5\end{array}$ & $\begin{array}{c}8 \\
124\end{array}$ & $\begin{array}{c}21 \\
129\end{array}$ & $\begin{array}{c}72 \\
-\end{array}$ & - \\
\hline $\begin{array}{l}\text { Bacterial vaginosis } \\
+ \\
-\end{array}$ & $\begin{array}{l}80 \\
60\end{array}$ & $\begin{array}{c}60 \\
100\end{array}$ & $\begin{array}{l}140 \\
160\end{array}$ & $\begin{array}{c}57.1 \\
-\end{array}$ & $\begin{array}{r}- \\
62.5\end{array}$ \\
\hline $\begin{array}{l}\text { Immunoassay Kit: } \\
\text { Chlamydia } \\
+ \\
-\end{array}$ & $\begin{array}{l}20 \\
38\end{array}$ & $\begin{array}{c}0 \\
242\end{array}$ & $\begin{array}{c}20 \\
280\end{array}$ & $\begin{array}{c}32.2 \\
-\end{array}$ & $\begin{array}{c}- \\
100\end{array}$ \\
\hline
\end{tabular}

\section{Comparison of Sensitivity and Specificity of the Various Methods and Techniques against Culture}

Direct microscopy for Chlamydia was sensitive by $56.4 \%$ and specific by $97.8 \%$. Candida was sensitive by $62.5 \%$ and specific by $85.7 \%$. Trichmononas had sensitivity of $85.7 \%$ and specificity of $86 \%$ while BV was detected with a sensitivity of $78.5 \%$ and specificity of $62.5 \%$ (Table 3). Stained smears after culture for Chlamydia had $80 \%$ sensitivity and $87.1 \%$ specificity. Candida had $75 \%$ sensitivity and $54.5 \%$ specificity. Trichomonas had $72 \%$ sensitivity and $94 \%$ specificity. Stained smear detection for BV was $57.1 \%$ sensitive and $62.5 \%$ specific. Immunoassay detected Chlamydia by $32.2 \%$ sensitivity and 100\% specificity (Table 3 and 4).

\section{DISCUSSION}

Although it is known that Chlamydia and vaginitis constitute problems of the female genital tract, the specificity of identification of causal agents often poses problems to the microbiology laboratory (Prey 1999; Franklin and Monif, 2000). Identification of Chlamydia was done in the early 1960's. In this earlier study, Embryonated Hen's Eggs were used and animals such as baboons (Grayston et al., 1960; Schacter et al., 1967) gave insights to the proper identification of Chlamydia. Control of bacterial sexually transmitted diseases was espoused by Schmid et al. (2005), who analysed the various component of vaginitis. Although the analyses were done in details to to effect prompt diagnosis. Similar findings were show the existence of such related problems in the female genital tract, but did not solve the problem of diagnosis. This present study showed a relationship between microscopy and culture and formed a strategy which combined their various identification approaches in a linear method for prompt diagnosis.

Unlike earlier studies which were based on various methods (Nugent et al., 1991), the high rate recorded by direct staining of samples and wet mount microscopy in our study revealed that organisms colonising the genital areas may also become pathogenic. Agents of vaginitis colonised healthy individuals Gaur et al. (2010), making bacterial vaginosis a subject of controversy as to when it should be regarded as true infection. To further elucidate the problem associated with diagnosis, it was shown that the detection of Chlamydia in groups of women from O/G, FP, STI and healthy controls showed a gradient in rates of Chlamydia detected by kit (32\%), microscopy $(56.4 \%)$ and culture (80.6\%). These findings agree with previous suggestions that laboratory results should be matched with clinical symptoms (Bradshaw et al., 2005; Oakeshott et al., 2006; Lowe et al., 2009).

An association of Chlamydia with other pathogens was shown by a $p$-value which increased as $f$ value increased indicating co-infection. The significance of $x^{2}$-value is that Candida and BV will likely occur in Chlamydia positive females confirming a channel for combined tests observed for Candida, Trichomonas and BV as 
regards rates of detection. Although, syndromic treatment of non-gonococcal urethritis, mucopurulent cervicitis and Pelvic Inflammatory Disease (PID) has been shown to be effective for managing those caused by Chlamydia trachomatis as well as agents of vaginitis, this approach is insensitive since a large number of asymptomatic individuals would not be treated (Schacter, 1990; Schacter, 1994). As shown in this study, candidiasis was highest in asymptomatic females; the healthy (control) group. Thus supporting the findings of Loeffelholz and colleagues (1992), which recommended laboratory based screening of asymptomatic females.

The recorded high percentage of infection in the brothel/hotel and STI groups were related to the increased rates of detection by microscopy. The observed rates for Candida albicans and bacterial vaginosis as shown by microscopy of wet mount, revealed the shapes of the pathogens which are indices for detection. Microscopy of stained endocervical secretion for Chlamydia showed inclusions $(56.4 \%)$ while culture $(80.65 \%)$ was most revealing. Although growth /colonies were recorded in cultivation media but they were nonspecific as microscopy after staining revealed the actual organism. Culture requires further biochemical tests for confirmation of organism, this may not be necessary for routine diagnosis except for research purpose. Our findings however showed that there were no significant difference between direct microscopy of fresh samples and results of stained smear after culture except for bacterial vaginosis which had $57.9 \%$ direct microscopy and $42.1 \%$ stained smear after culture. This was probably due to lack of anaerobic culture. Therefore, direct microscopy of sample may be substituted for culture in routine laboratory analysis (Willet et al., 2005).

The sensitivity of culture for Chlamydia has been estimated to range from 50 to $80 \%$ in laboratories with advanced experimental procedures (Schacter et al., 1994). Same applies to culture of agents of vaginitis (Hiller, 1993). In this present study, direct microscopy of Chlamydia gave a resolved sensitivity of $56.4 \%$ and specificity of $97.8 \%$. It is intermediate in screening high risk group but it is specific and useful for diagnosis of negative cases; those that do not have the disease. Stained smear after culture was both sensitive (80\%) and specific and may therefore be useful for routine screening and detection of Candida. Wet mount microscopy of vaginal secretion showed sensitivity (62.5\%) and specificity $(85.7 \%)$ and may not be recommended for routine use but could useful for diagnosis in asymptomatic cases due to its high specificity. For Trichomonas vaginalis, wet mount is both sensitive and specific for detecting the pathogen and microscopy of stained colonies is also useful. As previously proposed by Romanik et al. (2005), the sensitivity $(78.5 \%)$ for BV by wet mount depends on identification of clue cells. It is sensitive and useful for high risk group such as brothel/hotel and the STI clinic group.

Alternative tests for Chlamydia detection have included enzyme immunoassays, DFA and rapid antigen tests in addition to molecular assays (Johnson and Horner, 2008). The results of this study also show that communities which do not have access to sophisticated equipment and reagents could carry out simple and cost effective microscopic technique to identify Chlamydia and vaginitis in an "All-in-one procedure". Our findings showed immunoassay for Chlamydia as $32.2 \%$ sensitivity, therefore not useful for routine use. It had a specificity of $100 \%$ and therefore could be useful for diagnosis in those that do not have chlamydial infection. The wet mount is useful for Candida, Trichomonas and BV while stained endocervical secretions in addition to immunoassay will be useful in detecting $C$. Trachomatis in high risk group and highly specific in diagnosis in population where the disease is absent.

\section{CONCLUSION}

Microscopy of stained sample is useful for detecting Chlamydia for routine diagnosis and specific where disease is absent, but immunoassay is not sensitive for routine use. Wet mount has high sensitivity and specificity for detecting agents of vaginitis for routine use and diagnosis where disease is absent and therefore more cost effective for identification. Therefore for effective laboratory diagnosis of adult females who present with genital problems, this "All-inOne Combined-Procedure" is recommended as follows: for chlamydiasis and vaginitis, two forms of microscopy are required: (a) dry mount and (b) wet mount. The dry mount will require staining of endocervical sample with Giemsa stain for diagnosis of chlamydial infections; 1-4 inclusion bodies depicts mild infection; 5-10 inclusions or more depicts active infections. Observation of Gram-negative coco-bacilli, that is, Gardnerella vaginalis in Gram stained HVS for diagnosis is an indication for BV in clue cell positive samples. 
Depending on concentration of Candida and trichomonads in discharge, Gram positive yeast cell and pear shaped organisms indicate Candida and trichomonads respectively. Wet mount is strictly for vaginitis and presence of clue cells indicates BV; yeast cells and hyphae for Candida albicans and jerky movement of pear shaped organisims for trichomonads.

\section{ACKNOWLEDGEMENT}

We are grateful to Prof. Tolu Odugbemi (College of Medicine, UNILAG) for supporting the study with some reagents and Prof. Oni Idigbe (NIMR, Lagos) for his contribution to the proposal and Mrs. Ajala (Department of Medical Microbiology, College of Medicine, UNILAG) for her assistance in preparing reagents.

\section{REFERENCES}

Amsel R, Totten PA, Spiegel CA, Chen KC, Eschenbach S and Holmes KK (1983). Nonspecific Vaginitis. Diagnostic Criteria and Microbial and Epidemiologic Associations. Am J Med. 74: 14-22

Black CM (1997). Current Methods of Laboratory Diagnosis of Chlamydia trachomatis Infections. Clin Microbiol Rev. 10:160-184

Bradshaw CSW, Morton AN, Garland SM, Horvath LB, Kuzevska I and Fairley CK (2005). Evaluation of Point-of-care test, BV blue, Clinical and Laboratory Criteria for Diagnosis of Bacterial Vaginosis. J Clin Microbiol. 43:1304-1308

Cates W, Rolfsd RT and Aral SO (1990). Sexually Transmitted Diseases, Pelvic Inflammatory Diseases: An Epidemiologic Update. Epidemiol Rev. 12:199-220

Centres for Diseases Control and Prevention (1993). Chlamydia trachomatis Infections. Policy Guidelines for Prevention and Control. Morbid Mortal Weekly Rep. 42:1- 39

Chaltopadyad B (1984). The Role of Gardnerella vaginalis in "Non-specific" Vaginitis. J Infect Dis. 9:113

Cowan ST and Steel KJ (1993). Manual For the Identification of Medical Bacteria. $3^{\text {rd }}$ Edition, Cambridge University Press, London. Pp: 317

Friedek D, Ekiel A, Chelmicki Z and Romanik M (2004). HPV, Chlamydia trachomatis and Genital
Mycoplasmas Infections in Intraepithelial Lesions (LSIL). Ginekol Pol. 75:457- 463

Franklin TL and Monif GR (2000). Trichomonas vaginalis and Bacterial Vaginosis. Co-existense in Vaginal Wet Mount Preparations from Pregnant Women. J Reprod Med. 42(2):131-134

Gaur Sk, Frick KD and Dandolu V (2010). A Cost Effectiveness Analysis of Rapid Yeast Detection Kits. Women's Health Issues. 20: 75-79

Greeblatt RM, Shann SM, Brady SK, mammen Tobin AG, Evans AL and Lee RA (2005). Recurrent Bacterial Vaginosis: The Use of Maintenance Acidic Vaginal Gel following Treatment. Int J STD. 16:736-738

Hadgu A and Stemberg M (2009). Reproducibility and Specificity Concerns Associated with Nucleic Acid Amplication Tests for Detecting Chlamydia trachomatis. Eur J Clin Microbiol Infect Dis. 28: 915

Hilber AM, Francis SC, Chersich M, Scott $P$, Redmond S, Bender N, Miotti P, Temmerman M and Low N (2010). Intravaginal Practices, Vaginal Infections and HIV Acquisition: Systematic Review and Meta-Analysis. PLOS ONE.5: e9119: available at www.plosone.org

Hiller SL (1993). Diagnostic Microbiology of Bacterial Vaginosis. Am J Obstet Gynaecol. 169:455-459

Jespersen DJ, Flatten KS, Jones MF and Smith TF (2005). Prospective Comparison of Cell Cultures and Nucleic Acid Amplication Tests for Laboratory Diagnosis of Chlamydia trachomatis Infections. J Clin Microbiol. 43 (10): 5324-5326

Johnson AM and Horner P (2008). A New Role for Chlyamydia trachomatis Serology. Sex Transm Infect. 84:79-80

Loeffelholz MJ, Lewinski CA, Silver SR, Purohet AP, Herman SA, Buonaguno DA and Dragon EA (1992). Detection of Chlamydia trachomatis in Endocervical Specimens by Polymerase Chain Reaction. J Clin Microbiol. 30: 2847-2851

Lowe NC, Neal JL and Ryan-Wenger NA (2009). Accuracy of the Clinical Diagnosis of Vaginitis Compared to a DNA Probe Laboratory Standard. Obstet Gynecol. 113: 89-95 
Moncada J, Schahfer J, Bolan G, Engelman J, Howard L, Mushawar I, Ridgway G, Mumtaz G, Stamm W and Clark A (1990). Confirmatory Assay Increases Specificity of the Chlamidiazyme test for Chlamydia trachomatis Infection of the Cervix. J Clin Microbiol. 28:1770-1773

Newhall WJ, Johnson RE, Delisle S, Fine D, Hadgua, Matsuda B, Osmond D, Campbell J and Stamm W (1999). Head to head Evaluation of Five Chlamydia Tests Relative to a Quality Assured Culture Standard. J Clin Microbiol. 37:681-685

Nugent RP, Krohn MA and Hiller SL (1991). Reliability of Diagnosing Bacterial Vaginosis is Improved by a Standardized Method of Gram Interpretation. J Clin Microbiol. 29:297-301

Oakeshott P, Hay P, Steinke F, Rink E and Kerry $S$ (2006). Association between Bacterial Vaginosis or Chalmydial Infection and Miscarriage before 18 Weeks Gestation. Prospective Community-based Cohort Study. BMJ. 325:13341340

Prey M (1999). Routine Pap Smears for the Diagnosis of Bacterial Vaginosis. Diagnostic Cytopathol. 21:10-13

Romanik M, Kiel A, Friedek D and Martirosian G (2005). Can Chlamydial Cervicitis Influence Diagnosis of Bacterial Vaginosis? J Clin Microbiol. 43: 4914-4915

Romanik M and Martinosian (2004). Frequency, Diagnostic Criteria and Consequence of Bacterial
Vaginosis in Pregnant Women. Preg Epidemiol. 58:547-553

Schacter J (1967). Isolation of Bedsoniase from Human Arthritis and Abortion Tissues. Am J Ophthamol. 63: 1082-1086

Schacter J (1990). Chlamydial Infections. West J Med. 153: 523-534

Schacter J, Stamm WE, Quinn TC, Andrew WW, Burvczak JD and Lee HH (1994). Ligase Chain Reaction to Detect Chlamydia trachomatis Infection of the Cervix. J Clin Microbiol. 32:25402543

Schmid GP, Steen R, and N'Dowa $F$ (2005).Control of Bacterial Sexually Transmitted Diseases in Developing World is Possible. Clin Infect Dis. 41(9):1313-1315

Stamm WE, Tam M and Cles L (1983). Detection of Chlamydia trachomatis in McCoy Cell Cultures with Fluorescence in Conjugated Monoclonal Antibodies. J Clin Microbiol. 7:666-668

Willet L L and Centor RM (2005). Evaluating Vaginitis: The Importance of Patient Factors. J Gen Intern Med. 20 (9): 871

Wilson JD, Shann SM, Brady SK, Mammen Tobin $A G$, Evans AL and LKee RA (2005). Recurrent Bacterial Vaginosis: The Use of Maintenance Acidic Vaginal Gel Following Treatment. Int $J$ STD. 16:736-738 